\title{
ANALYSIS OF THE TECHNICAL AND TACTICAL MASTERSHIP OF THE FEMELE WORLD WRESTLING SHAMPIONS - 2018
}

\author{
Carolina Grozdanova \\ National Sports Academy „Vassil Levski”, Sofia, Bulgaria
}

\begin{abstract}
The technical and tactical analysis aims to control and optimize the training process in wrestling. The analysis is a main tool for intelligence of the adversaries in order to build a general strategy for the respective championship or stage of preparation. The analysis allows the logarithmic preparation and improvement of the wrestlers technical and tactical profile based on real and objective information about the technical training of concurrent.

The aim of the present study is to analyse the technical-tactical profile of female wrestling champions in the different categories and to trace the dynamics and variety of the technical skills used by them.

The study was conducted with data from the World Wrestling newsletters of the World Wrestling Championship in 2018 in Budapest, Hungary.

Through the benchmarks and criteria for technical and tactical efficiency of the female wrestlers and their categories at the Women World Wrestling Championships in 2018, we have found that technical performance has high values mainly in the low and middle categories, which is based on good speed training and the appropriate ratio of muscle mass and net body weight female wrestlers. The high level of competition among female wrestlers at world level places them at a relatively uniform level of speed-power abilities. The technical and tactical skill of the female wrestlers and their diversity is based on the specifics of the respective wrestler's schools and the individual profile of the female wrestlers.
\end{abstract}

Key words: techno-tactical analysis, female wrestling, mastery

\section{INTRODUCTION}

The whole training of female freestyle wrestlers is linked to a strategic goal, objectives and plans. Technical training in wrestling plays a key role for building the model of wrestlers.

The application of technical repertoire is linked to a specific strategy, which is expressed in a complex and dynamic system of management and regulation of the development of sports, the sport training and the running of the competition. The two sides of the wrestling training - technique and tactics determine the technical and tactical skills of wrestlers (Barna, 2011; Kirov, Makaveev, 2010; Makaveev, 2016; Mysnyk, Davis, Simpson, 1994).

Combat techniques and tactics are multidimensional spheres with an infinite range of elements connected in a complex dialectical relationship. The application of technical-tactical actions is always an integral process, as it is the result of complex processes and coordination relationships between the systems of human body. The external manifestation of the technical and tactical actions is judged by the judges according to the result and the aesthetic evaluation for expression and perfection of execution. The form of the technical-tactical actions in wrestling expresses the core connection of the interaction of the elements that form its content. The technical-tactical mastery in the time of modern Olympics is characterized by intensive integration as: the technique is associated with a larger element of technical preparatory movements (grips, protections and counters links are combined in combinations and technical-tactical complexes, tactical means are associated in algorithmic schemes, the execution of the fights correlates more closely with the level of motor abilities, etc.) (Petrov, 1969, 1977, 1978).

In the context of modern concurrence in women's wrestling, an increasing variety of technical and tactical skills is required. The physical and functional capacities of the wrestlers are almost equal, which makes the unification of technical and tactical capacities the most important part of the training of the female wrestlers. Each female 
wrestler has an individual style of combat, which makes the technical and tactical preparation a complex and multidimensional system.

The hypothesis of this study is formulated as following: the technical-tactical mastery of female wrestlers concerning the application of technical-tactical actions in competitive conditions is with greatest variety for the smaller categories (50kg and $53 \mathrm{~kg}$ ) than for heaviest - $72 \mathrm{~kg}$ and $76 \mathrm{~kg}$.

\section{Aim and objective of the study}

The purpose of our study was to determine the variety and applicability of the gripes in the competitive conditions (European Girls Championship 2019) for different categories.

The main task was the study of video materials from the championship with detailed algorithmic notes of the applied technical actions (grips) and their effectiveness (received technical points).

\section{METHOD}

The research methodology contains the video analysis and statistical methods for summing up the technical points and using them to compare between different categories. Video analyses of 149 competitions from the European Championship for Girls in Pontevedra, Spain, were processed. The 25 countries participating in the championship, with a total of 126 competitors in 10 categories.

\section{RESULTS}

From video survey of the European Girls. Championships, 2019 in Pontevedra, Spain it can be seen that the most used technique in $50 \mathrm{~kg}$ category (Figure 1) is Half Nelson (21 attempts) and the points won are the 42 technical points. The second is Far arm drag and near leg pick up, which is performed in parter position (15), and the points won are 30 technical points. In standing position, the most commonly performed grip is hip throw with arm and neck hold - 6 and the 18 technical points won. Double Leg pick up is a typical for free wrestling. It is the second most commonly used technical tool in this category. The total number of points won in the category is 198 technical points.
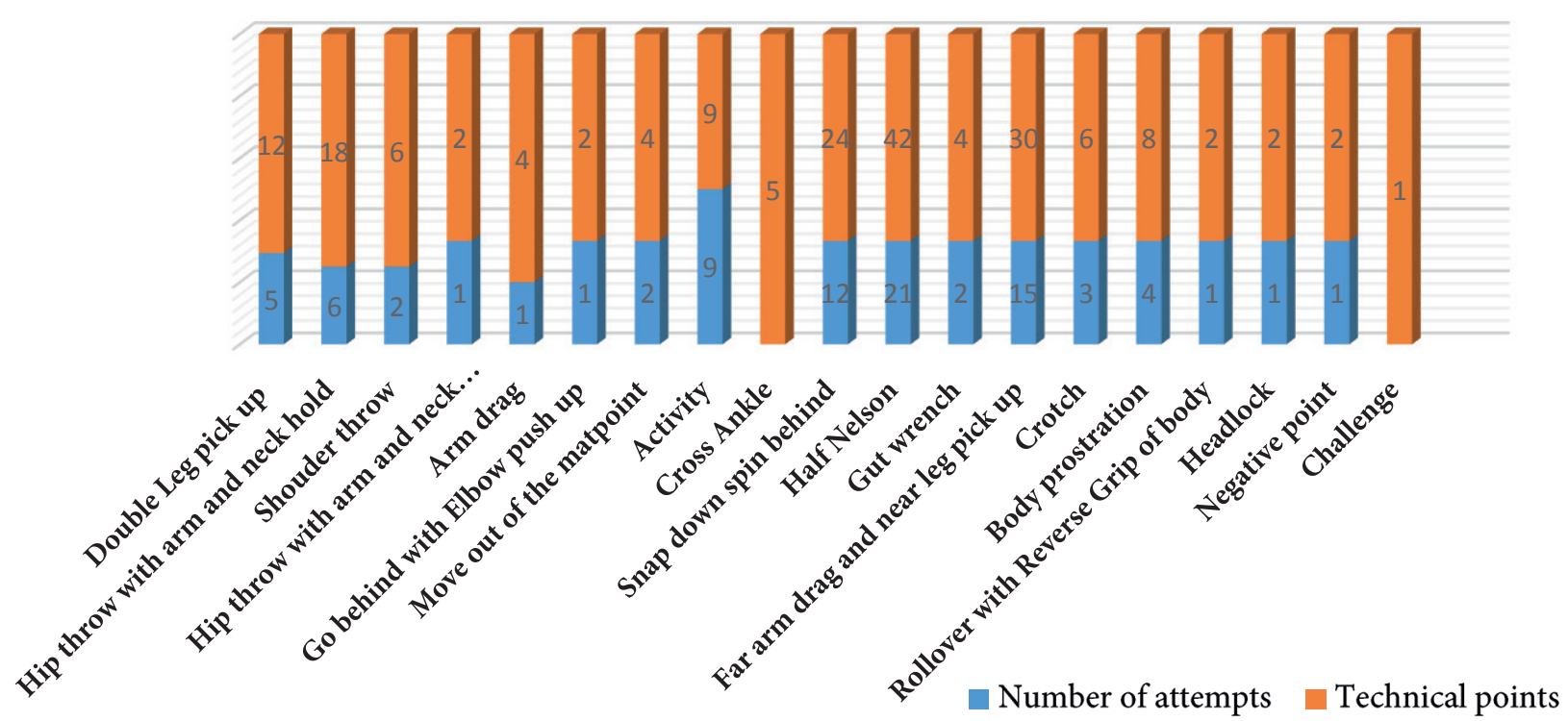

Figure 1. Technical-tactical mastery in the category up to $50 \mathrm{~kg}$

Figure 2 shows the technical tools used in the category up to $53 \mathrm{~kg}$ during the European Championship for girls. In standing position, the most commonly used grip is Leg pick up - 7 attempts, and points won are 14 technical points. Double leg pick up is the second - 4 attempts and 8 tech- nical points. In parter position, the most used technical means is snap down spin behind - 18 attempts and 37 technical points, as well as gut wrench - 9 - attempts and 18 technical points. The total number of points won in the category is 143 technical points. 


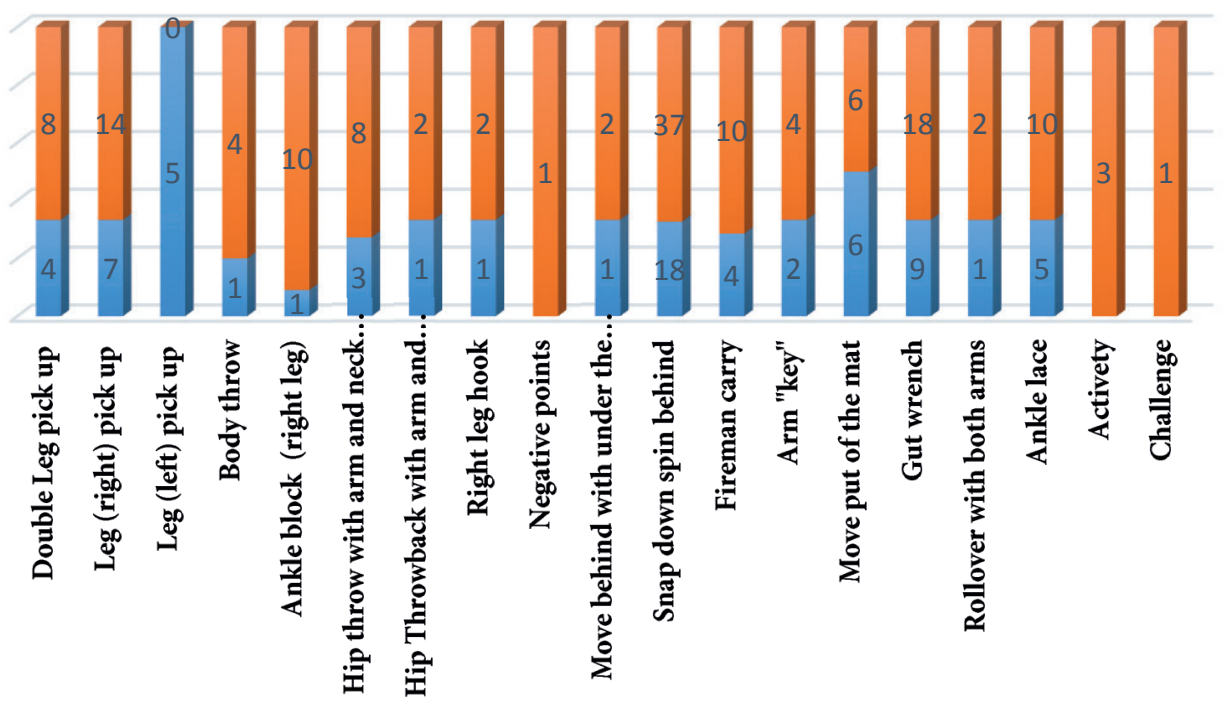

Number of attempts $\square$ Technical points

Figure 2. Technical-tactical mastery in the category up to $53 \mathrm{~kg}$

On Figure 3 it can be seen that the most used tech- and 12 technical points and "cross" / cross ankle/ - 3 nical tool in category up to $72 \mathrm{~kg}$. from the standing pts. and 6 technical points won. The total number position is leg (right) tackle -8 ps. with 16 techni- of points won in this category is 93 technical points. cal points won. On the second place is the double legs tackle -7 attempts with 16 technical points Figure 4 shows the results in category up to $76 \mathrm{~kg}$ won. The equality in the points won from the two from which can be seen that the wrestlers have won technical actions going from the fact that at the cra- the biggest number of points from the standing podle, the awarded points for execution are 2 points sition with a move out of mat point - 5 technical each, and from the leg tackle one of them is rated 4 points from 5 executions. Equal number of attempts points, and the others by 2 pts. In parter position, ( 3 pcs) are from right leg tackle, hip throw with arm the most common technique is gut wrench -6 pts and Fireman carry and from activity points.

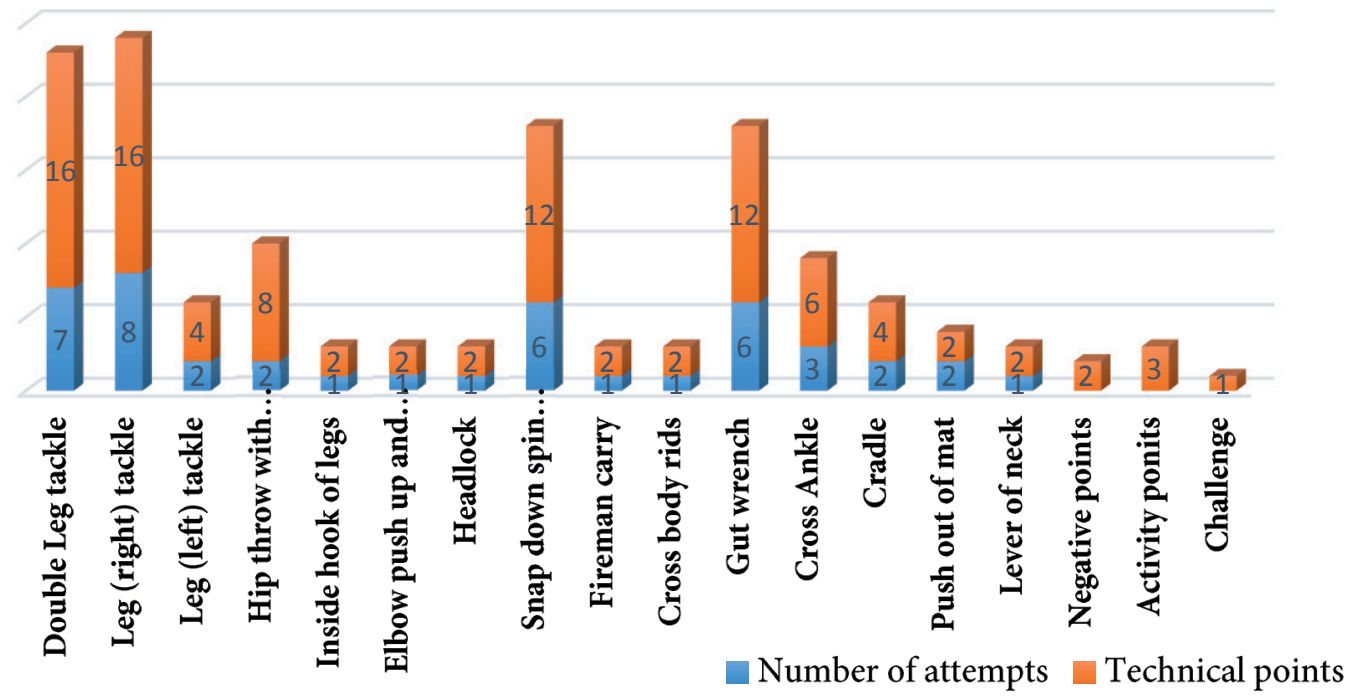

Figure 3. Technical-tactical mastery in the category up to72 $\mathrm{kg}$ 
In parter position, the most commonly used technical action is snap down spin behind 11 pcs and 21 technical points. and rollover with double arms -4 attempts and 8 technical points. The total number of points won in the category is 97 technical points.
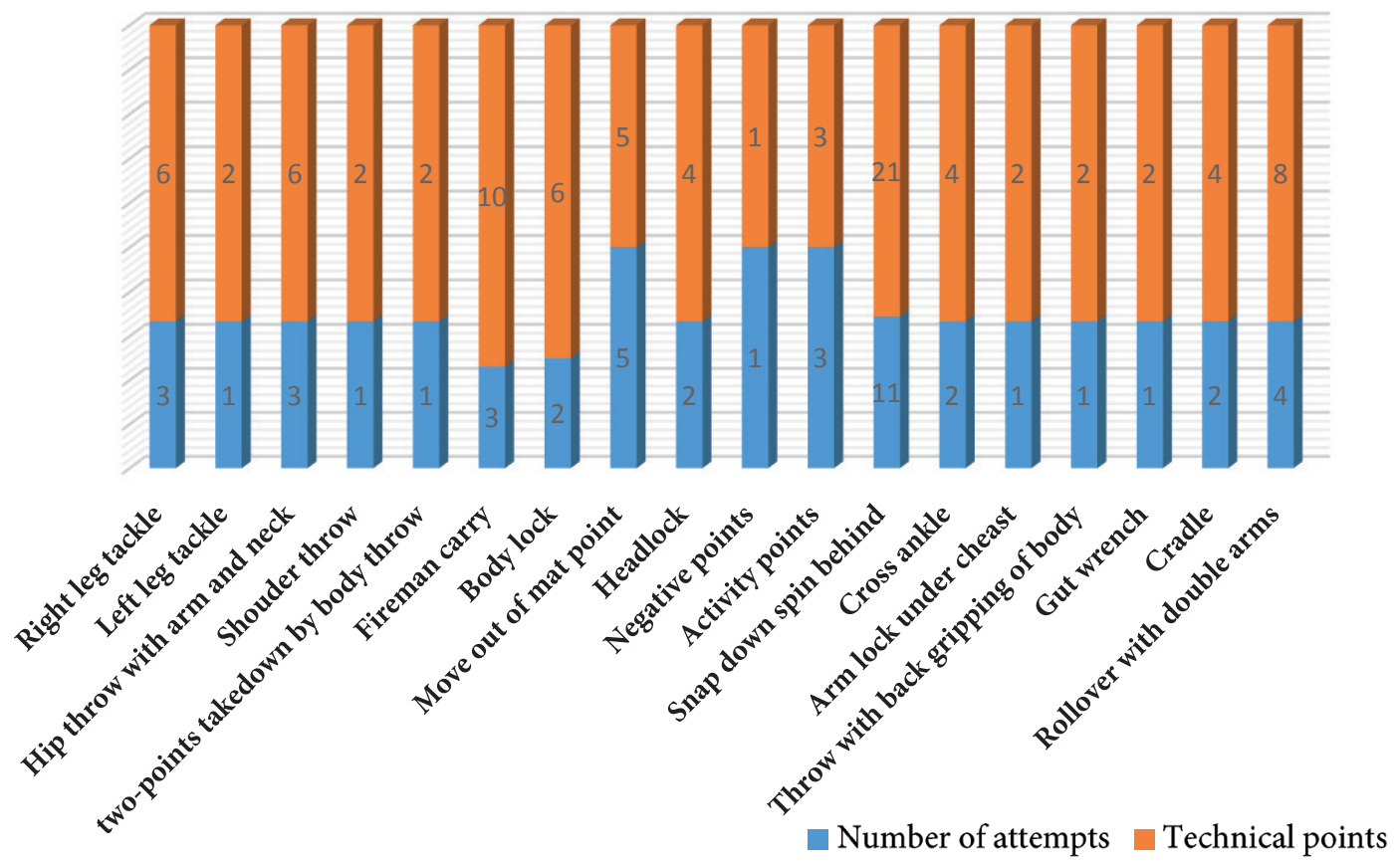

Figure 4. Technical-tactical mastery in the category up to $76 \mathrm{~kg}$

\section{DISCUSSION}

The results show that the most commonly used posture grips during the Championship are the main types of footsteps - left foot, right foot, both. More attempts are made in the light categories - 50 $\mathrm{kg}$ and $53 \mathrm{~kg}$ in comparison with the categories 72 $\mathrm{kg}$ and $76 \mathrm{~kg}$.

1. In parter position, taken into account the category, the most commonly used technical action is snap dawn spin behind. The reason for this is that the gripes on parter position are mostly performed after snap dawn spin behind - gut wrench over a "bridge", "cross ankle", "cradle", etc.

2. The more technical points are won in the $50 \mathrm{~kg}$ category. - 198 points, and a minimum in category of $72 \mathrm{~kg}-93$ points, followed by the category of $76 \mathrm{~kg}-97$ points.

3. High competitiveness in women's wrestling requires an increasing variety of technical-tactical complexes and combinations, which necessitates a greater share of work in the preparation of women wrestlers.

4. The individual approach in the elaboration of the technical-tactical model of fight in women wrestlers are required.

\section{REFERENCES}

Barna, T. (2011). Wrestling made easy. Budapest, Hungary. 2011

Kirov, K., Makaveev, O. (2010). Sports training of the wrestlers. Sofia, NSA PRESS.

Makaveev, R. (2016). Control of preparation. Sofia, NSA PRESS.

Mysnyk, M., Davis, B., Simpson, B. (1994). Winning Wrestling Moves. Human Kinetics.

Petrov, R. (1969). Combat strategy and tactics. Sofia: Medicine and Physical Education.

Petrov, R. (1977). Free and classic wrestling. Sofia: Medicine and Physical Education.

Petrov, R. (1978). Improvement of the technical and tactical mastery of the fighter. Sofia, Medicine and Physical Culture, 1978

\section{Corresponding author: \\ Grozdanova Carolina} PhD student

National Sports Academy "V. Levski", Department "Wrestling and Judo" E-mail: kariwrestling@gmail.com 